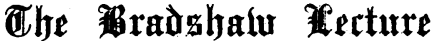
oN

\section{MISPLACED AND MISSING ORGANS,}

Delivered before the Royal College of Strgeons of England, November 8th, 1917.

BY

Sir JOHN BLAND-SUTTON, F.R.C.S., SURG̈EON TO THE MIDDLESEX HOSPITAL.

Thoul linoviest not . . . hou the bones do grou in the womb of her that is with child.-Eccles. $\mathrm{xi}, 5$.

THE monotony of order and regularity is impressed on us early'in the study of anatomy. The eagerness with which students draw the attention of demonstrators to abnormalities they find, when dissecting, is notorious. Constancy of position is not a virtue of viscera; but it is amazing that in ninety and nine bodies out of a hundred the abdominal organs fall into their proper placès during fetal life.

Until the main features of the development of animals were closely investigated, variations in the position of the

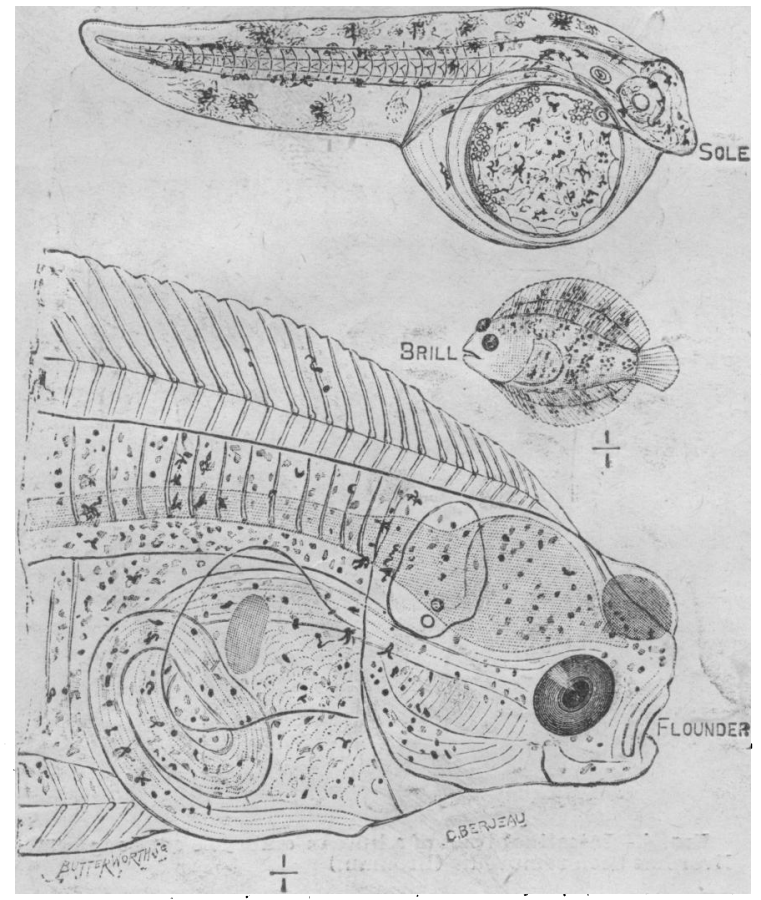

Fig. 1.-Larva of the sole, brill, and flounder.

(J. 'T. Cunningham.)

viscera aroused curiosity, and must have been as.ill understood as the reasons for the bilateral symmetry of the body. In the case of bilateral organs, such as the eyes, ears, teeth, kidneys, ovaries, and bones of the limbs, as well as the opposite halves of median organs like the brain, tongue, bladder, and uterus, the symmetry is astounding. Although there are minor variations in bilateral organs, the general likeness in shape is so close that the ability to distinguish between right organs and left organs is an examiration test for estimating the diligence of students in practical anatomy: The bone that fascinated me most is the stapes. It is the smallest bone in the skeleton, and thoroughly justifies its name. The right and the left stapes are so like each other that it is difficult to tell one from the other. They are as nearly alike as a pair of stirrups. He who doubts this should examine the unique collection of auditory ossicles in the Museum.

Not the least interesting feature of anatomical research is the detection of additional skeletal elements. It is not uncommon to find an extra vertebra in the lumbar set, or in the coecyx. Excess in nunber is no disadiantage, but occasionatiy half a vertebra is missing." When this happens it causes tilting of the spine. A study of available specimens slows that this anomaly may occur in any region of the spinal column. Such deficiency can be detected in radiographs of the spine, and it is often associated with spina bifida. Half-vertebiae have been found in fishes, snakes, calves and rabbits. Embryology has disclosed many secrets concerning missing organs: some parts true to the impress of heredity appear in the embryo and disappear with the gradual perfection of the fetus. Parker, studying the development of the "green turtle, noticed that the embryo possessed ten more somatomes than were represented by vertebrae in the adult. Seven were suppressed in the peck and three in the tail. . This suggests for turtles ancestors with longer necks and tails than existing forms. There can be no doubt that if turtles were dissected as thoroughly as they are made into soup many examples of supernumerary ceivical vertebrae would be found among them, in spite of the specialization that exists in the vertebral elements of the Chelonian neck. The best known example of a missing vertebra occurs in the sea-cow or manatee. As all students of human osteology know, this mammal has six, instead of seven, cervical vertebrae. Kiikentlial dis. covered another curious feature in this weird mammal: the fetal manatee has a thick coating of rudimentary hair, but the skin of the adult animal is, like that of the whale almost hairless. The abundance of hair on the fetal manatee indicates that manatees had ancestors as furry as seals. Long ago, John Hunter noted that whales and sea-cows, mammals living entirely in the water, could derive no advantage from hair, but they have an inmense quantity of stibcutaneous fat which is a worse conductor of heat than water. When the ancestors of the manatee took to water they lost their hair bnt gained fat. - Embryo. logy furnishes evidence concerning kinship and descent. Our thoughts may be turned in this direction when we eat

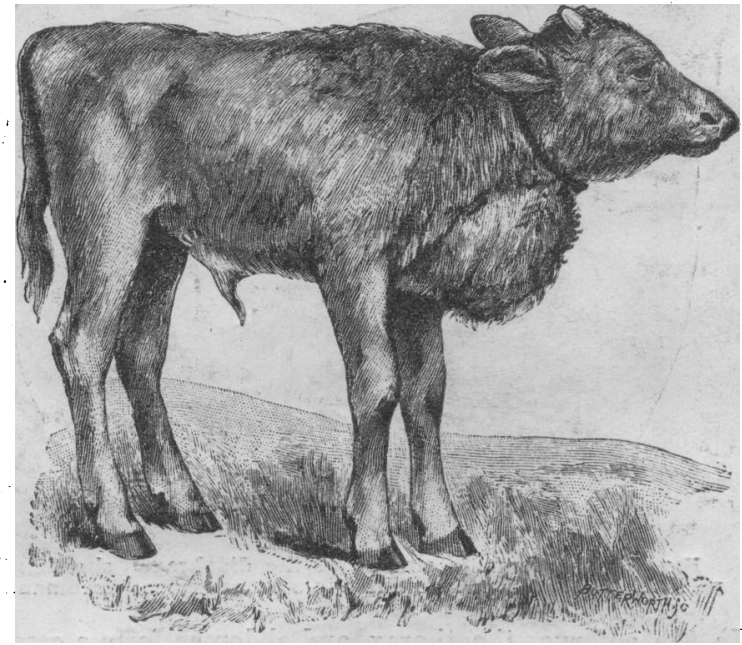

FIG. 2.-A calf of $2 \frac{1}{2}$ months with its heart in the dewlap.

a flat-fish. Sole, plaice, brill, dab, flounder, and halibut when first hatched are symmetrical and transparent; they have an eye on each side and swim in a vertical position. Later the fish flattens, and the facial portion of the skuli twists in such a way as to bring the eyes to the upper surface. The hinder part of the skull that contains the brain does not share in the twist. Sometimes a sole is found with an eye on the white or "blind" side. "Holt described an example in 1894. The larva of a flat-fish, so transparent when alive, is only rendered visible by the metallic brilliancy of the eyes, which shine through the transparent tissues like metal beads (J. T. Cunningliam). The alteration in the position of the eye influences the mode in which the little fish swims. For instance, in the -flounder (Fig. 1) the left eye projects above the edge of the head on the left side. The fish in this condition swims on its edge, slightly inclined to the left side. During the whole of the change, from a bilaterally symmetrical to a flat fish, the inclination from the vertical in swimming is proportional to the degree of asymmetry of the eyes.

\section{A Cerveal feart.}

Many mammalian organs migrate during embryonic and fetal life, and some of the ctranges in their position are as extraordinary as those of the eye of flat:fishes. Early in 
the study of human anatomy this matter comes forcibly to our notice when we study the recurrent course of the inferior laryngeal nerve, and realize that its unusual course is due to the transit of the heart from throat to thorax. There is nothing quite so fascinating as watcling the pulsating embryonic heart of a click lying clear of the body cavity, then to trace its gradual enclosure, translation, and final imprisonment by the completion of the walls of the body cavity. Occasionally the heart fails to reach its normal place, and is detained in the neck, an embryological accident not uncommon in calves. The clinical features of such an anomaly are striking. A calf (Fig. 2) was born near IIontrejeari (1902), and its owner sought the advice of Bourdelle on account of a globular pulsating swelling in its dewlap. The swelling, which was as big as a cocoanut, became soft and flaccid, then hardened suddenly, and sensibly diminished in volume. These changes happened regularly seventy times per minute synchronously with the pulsation in the arteries. There was no difficulty in recognizing the supposed tumour as the heart. The calf, which did not appear to suffer inconvenience from the anomalous position of its heart, was killed in order that a complete' anatomical examination could be made. The details are given with great care in tho Revue Vetérinaire, 1902. The thoracic cavity was much smaller than usual, partly due to an abnormally forward position of the diaphragm, which was also dis. placed by an unusually large liver. A cervical heart is a rare anomaly, but I will now describe something rarer.

An Intrathoracic Stovach.

The diaphragm is a muscle peculiar to mammals, and the long course of the phrenic nerves arouses curiosity.

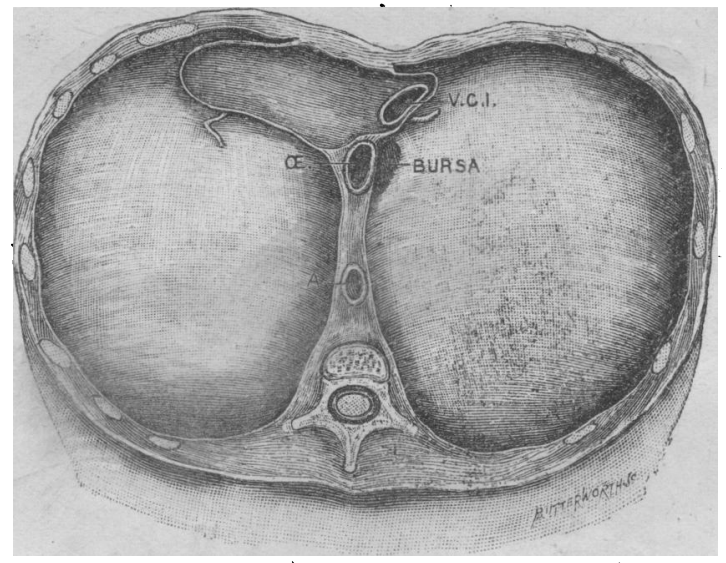

Fug. 3.-The thoracic surface of the diaphragm, showing the position of the infracaidiac bursa in a human fetus. (Broman.)

In the embryo, the thorax and abdomen form a common cavity, as in amplibians and reptiles. This pleuroperitoneal cavity is divided by the diaphragm into thoracic and abdominal cavities. The precise mode in which the diaphragm arises is not easily appreciable, and this muscular septum is liable to some gross defects. Deficiency of the left half of the diaphragm has often been recorded, and few pathological museums are without an example.

A child with a partial diaphragmatic hernia may survive its birth and attain adult life, but in the majority of patients with diaphragmatic hernia that come under the observation of surgeons the lesion is traumatic. Imperfections of the diaphragm allow the intestines and stomach to intrude into the thoracic cavity, and without the help of $x$ rays it would be difficult to diagnose such a condition with certainty. To day the stomach requires a section in textbooks of surgery to itself, and anomalies in the position of the stomach are of practical interest. I had an opportunity (1917) of studying an intrathoracic stomach presenting unusual features. A spinster, aged 26, complained of gastric disturbance of such severity as justified an examination with $x$ rays and an opaque meal. The radiographs disclosed the shadow of a body above the diaphragm, displacing the heart to the left. Two radiographer's of experience agreed that the intrathoracic shadow represented a stomach lying above the diaphragm. The patient's discomfort justified operation. The parts were exposed by a median supra-umbilical incision, but no stomach was visible. Then I found a cleft in the diaphragm on the right side of the oesophagus from which small intestine energed. On introducing my finger I foumd the stomach lying in a pouch extending into the thorax. I withdrew the stomach; it was of normal size, but had very thick walls, and on being released at once slipped out of sight into the pouch. The limits of the pouch were clearly indicated on the radiographs. The patient recovered from the operation, but suffers occasional discomfort and attacks of vomiting. Her digestive disturbances have not been relieved, nor eggravated by the interference. The pouch occupied by this vagrant stomach has an embryologic history. The region of the abdomen known as the lesser bag of the peritoneum is, for the Swedish anatomist Broman, the omental bursa. In the embryo it extends into the thorax on the right of the oesophagus. In the fetus a small pouch exists in this situation-the infracardiac bursa. In adults it may be cletected as a narrow slit (Fig. 3). Man, in common with other members of his class, has tivo pleural cavities; some monkeys possess a third thiat lodges the odd or azygous

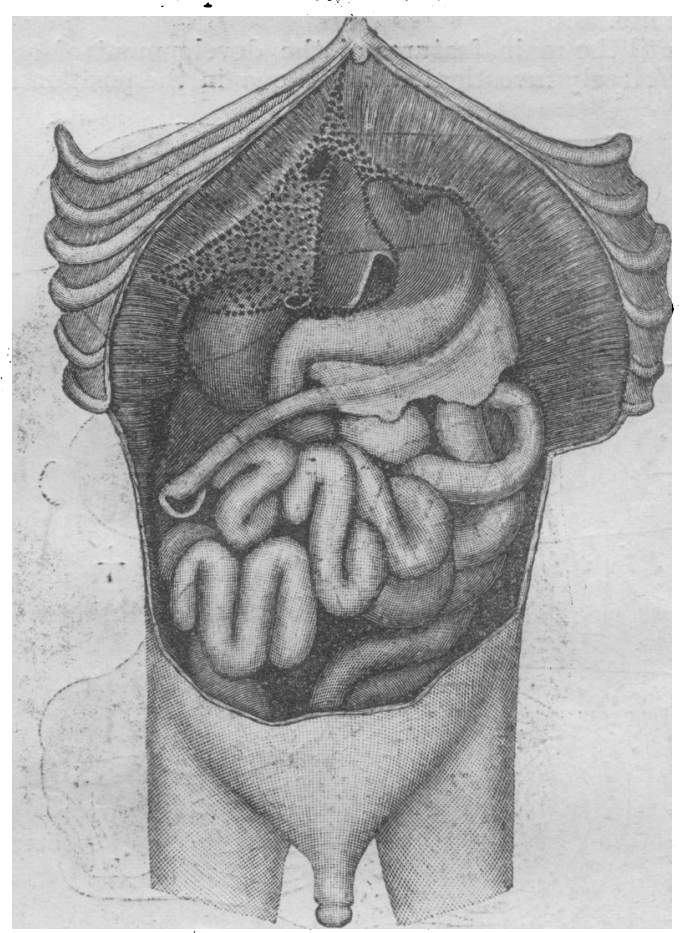

FIG. 4.-Intestinal tract of a human embryo $6 \mathrm{~cm} .10 \mathrm{gg}$. The liver has been removed. (Broman)

lobe of the right lung; : Simpson found one in a man (1507). The infracardiac bursa of the fetus represents the thirci pleural cavity. It was a cave in my patient and hid the stomach.

The Undescended Caecum.

Under normal conditions the caecum occupies the right iliac fossa, and in many, especially women, it dips into the right half of the pelvis. The clianges which take place in the disposition of the intestines, great and small, during fetal life are well known to anatomists. These movements lead to and end in the complicated arrangement of the peritoneal folds that cause despair to the novice in luuman anatomy.

In a large number of mammals the whole intestinal tract from the middle of the duodenum to the end of the colon is slung on a common mesentery. This is the arrangement found in the human embryo; it occasionally persists in adults, and leads to some remarkable displacements of the caecum that cause a very fatal form of intestinal obstruction. In the early embryo the caecum does not exceed in circumference a contiguous coil of ileum; even at this stage it is defined by the vermiform appendix (Fig. 4) and lies in contact with the under surface of the liver. Gradually enlarging, it descends to the normal position in the riglit iliac fossa. It is a common condition to find the caecum completely invested with peritoneum, and almost as nobile as a small ovarian cyst. Occasionally the caecum is retained in the fetal position, immediately under the liver. 
The alarming frequency of septic disease of the vermiform appendix leads surgeons to study keenly variations in the positions of the caecum and anomalies connected with its descent, for these determine the final situation of the appendix. Experience in the operating theatre teaches surgeons that the vermiform appendix may lie in any position between the under surface of the liver and the floor of the pelvis. I have on sereral occasions found its tip touching the gall bladder. When the appendix is retro. caecal, it often lies in contact with the kidney. I have carefully studied the retrocaecal appendix, not ouly on account of the difficulty that sometimes attends the thiagnosis of appendicitis when the appendix lies behind the caecum, but also to ascertain the causes which lead to this position. It admits, I think, of the following simple pxplanation. In many of the cases in which the appendix ies rertically behind the caecum its tip is firmly fixed

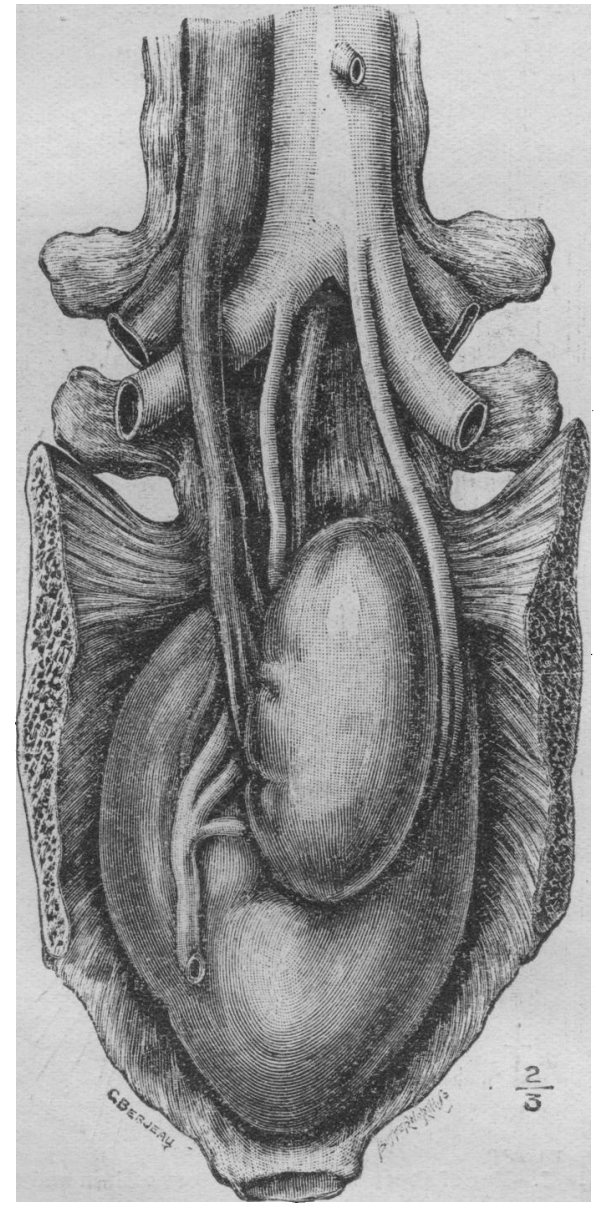

FIG. 5.-Pelvic kidney ; from a wan.

near the lirer. Thus it happens, if the tip of the fetal appendix is anchored, it canuot descend with the caecurn into the iliac fossa, but the descending caecum gradually lengthens the appendix. This will explain the fact, familiar to surgeons, that a retrocaccal appendix is often abnormally long, streight, and lacks a mesentery. Occasionally I have found the tip of a retrocaecal appendix so firmly fixed to the peritoneum in the loin that the caecum, though it has descended into the iliac fossa, has had its blind end turned upwards to the liver. In such a case the crecum is suspended by the appendix. The mechanism by which the caecum migrates is associated with that deter. mining the descent of the testes and the ovaries. Non. descent of the sexual glands is often associated with an undescended caecum, and those ill understood movements; or readjustments, of the peritoneum that occur at a late period of fetal life.

The Pelitic lífnes.

Some of the changes in the position of abdominal riscera are almost romantic. The extraodinary more ments culminating in the descent and extrusion of the testicles were detected by Haller in 1755; John Hunter described the process thoroughly in 1762, and left little for subsequent anatomists to discover. It is not generally appreciated that the kidneys undergo a $m$ urked translation during fetal life. Many year's ago, whilst making a post-mortem examination of a man, I found one of his kidneys in the hollow of the sacrum (Fig. 5); it received its blood supply from the right and the left common ilias arteries. I have seen a kidney in this situation in a woman; it was regarded before operation as a distended Fallopian tube. When the pelvic organs were exposed in the course of the operation a curious set of anomalies appeared. The uterus was of the unicorn variety and had a right ovary, tube, and broad ligament. The left side was smooth and round, and lacked appendages of every lind, including the round ligament. The right kidney was normal in position and slape. This woman conceived after the operation and was delivered withont difficulty, in spite of the kidney in the hollow of the sacrum.

A pelvic kidney may become hydronephrotic, and it has happened that a gynaecologist, unaware of this anomaly, remored such an organ under the impression that it was an ovarian cyst. The retention of a kidney in the hollow of the sacrum admits of an explanation.

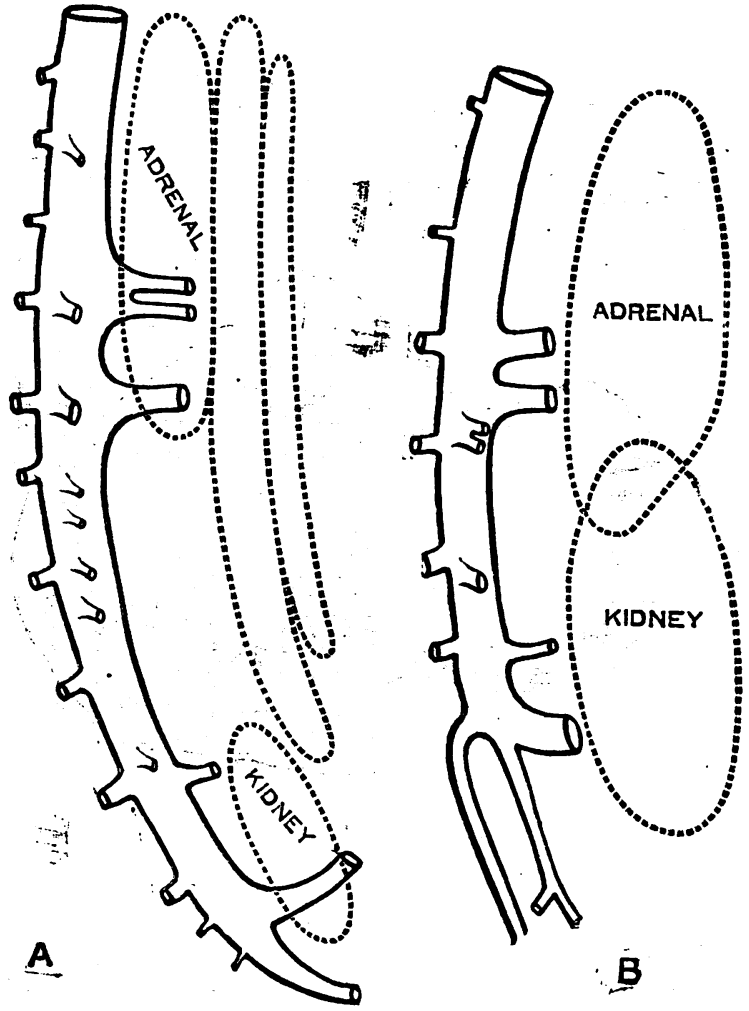

FIG.6.-Diagrams to show the varying relations of the adienal and kidney in the human embryo. (Bromen.)

The position of the kidney in the human embryo is influenced by the size of the adrenal. During intranterine life the adrenals are large and conspicuous. In the first half of the second month the adrenal is double the size of the kidney and the tro organs are widely separated (Fig. 6, A). Then the lidney grows faster than the adrenal. At the end of the second month they are equal in size, and subsequently the lidney becomes the more conspicuous organ. The relationslip of the kidney to the iliac arteries (Fig. 6, B) in the embryo explains the occasional occurrence of a pelvic kidney in, or near, the pelvis.

The close proximity of the kidneys in the pelvic region of the embryo helps us to understand the origin of the common anomaly known as horseshoe kidncy, in which the two kidneys are more or less intimately joined by thei: lower poles, and the ureters usually lie in front of tro renal isthmus. In one example I have seen both halves of such a kidney hydronephrotic and the isthmus passed across the pelvis below the promontory of the sacrum.

The large size of the adrenal in the human embrio is clie to the preponderance of the cortex over the medullary portion (T. R. Elliott), and this is in some subtle wav 
correlated with the development of the cerebrum. The hypertroplyy of the adrenal cortex in embryonic life is a feature peculiar to human fetuses, and if the cerebrum fails to develop, as in anencephalous human fetuses, the proportions of cortex and medulla are like those of other mammals. It is said that Morgagni (1723) knew of this

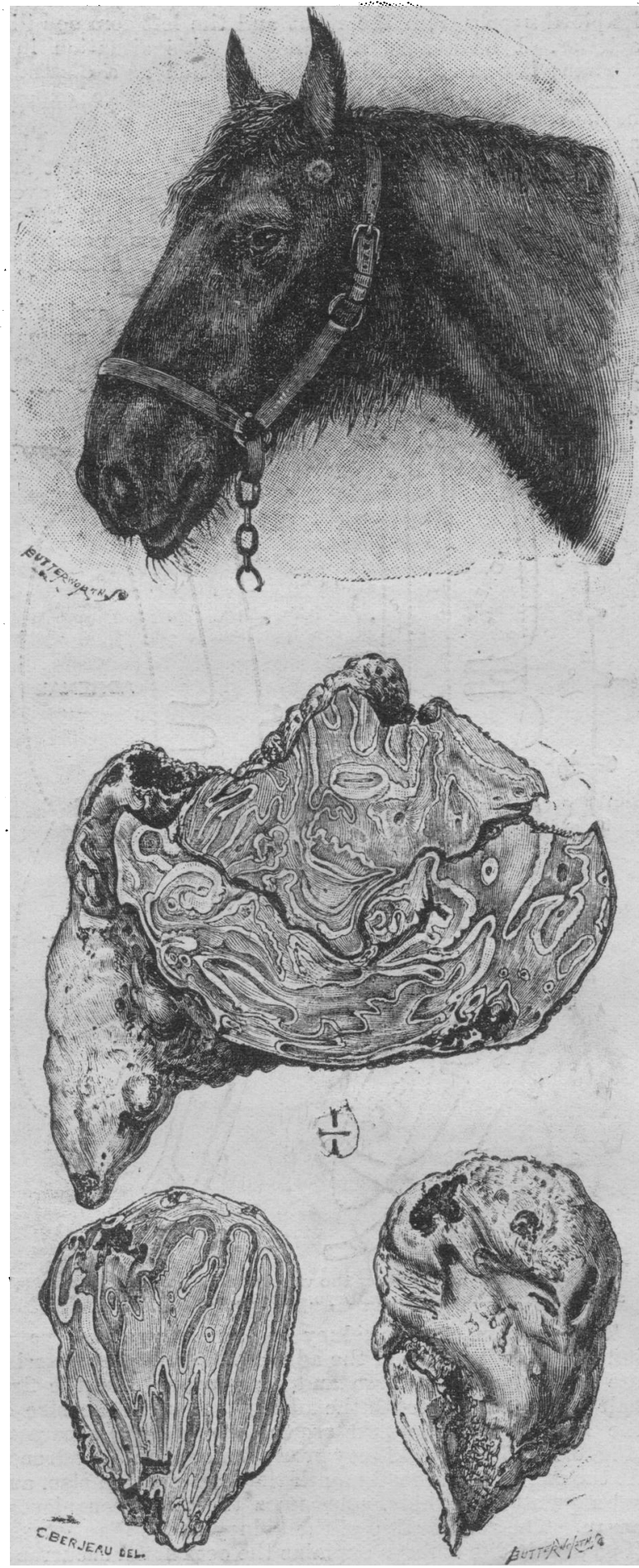

Fis. 7.- Head of a mare with a sinus leading to some mastoid teeth. The drooping lip shows palsy of the facial nerve. The teeth are shown below, two in section. (From I'umours, 6th ed.)

corvelation between the corebrum and the adrenals, but I have failed to find the statement in his Letters.

Although I have collected half a score examples of pelvic kidneys in men and women I have failed to obtain any avidence of pelvie lidneys in other mammals. This may be used as aditional evidence that the candal displace. went of the Extrey in the human embryo is due to the predominange of the adrenal cortes
Specific Organ.rorming Substances,

The correlation between the cortex of the adrenal and the cerebrum leads us to the consideration of what are known as specific organ-forming substances. This may be exemplified by an experiment on the developing eye." The chief features in the formation of the eye of a vertebrate animal are well linown. The essential nervous elements of such an eye are furnished by the optic vesicle, an out. growth from the brain. The lens begins as a circum. scribed thickening (or plakode) of the surface epiblast, which is received into the hollow formed by the invagina? tion of the optic vesicle. Lewis, in the course of some remarkable experiments performed on tadpoles, cut off the optic vesicle, and pushed the amputated organ under the skin to a nerv place; no lens was formed in the normal position, but a lens-like structure developed from the slin situated over the optic vesicle.

This specific organ-forming influence can be studied in the poultry yard. Hens have only one ovary and oviduct

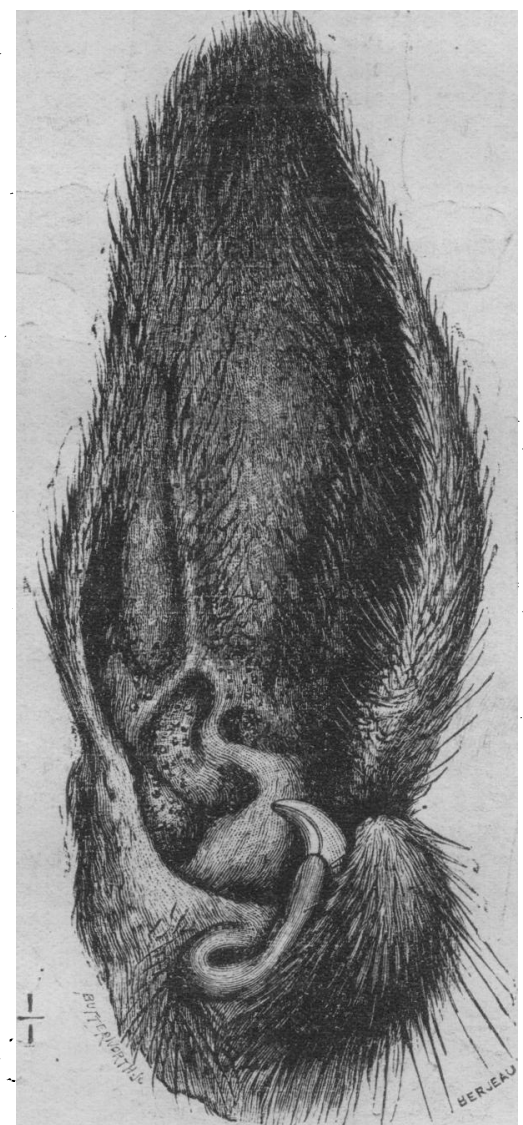

Fig. 8.-Ear of sheep with an accessory ostinm and tooth.

- the left. The right orary and duct-are missing. Often the absent oviduct is represented by a vestige attached to the cloaca. In winter the left ovary is small and insignificant, and the oviduct a mere thread. In spring the ovary is the most conspicuous organ in the abdomen, and the oviduct becomes enlarged, convolutod, and resembles intes. tine in size and appearance. It is reasonable to believe that some specific secretion, formed in the ovary, stimulates growth and tissue formation in the oviduct, and the vestigial condition of the right ovidnct of birds is correlated with the absence of the corresponding ovary. The influence of glandular activity on tissue-production is. remarkable: No one las seen an eye without an optic nerve, or a gall bladder without a liver, a ureter without a kidney, or a uterus without a sexual gland. I have seen and described a uterus in a boy, but there vere testes associated with it. There is a side issue connected with the missing ovary in birds that is worth mention. From very ancient times men and women have believed that the right ovary furnishes boys and the left ovary girls. Many medical men believe it to-day; the tradition is deeply rooted; it has no foundation. As hens have only one ovary, the left, those who believe this tradition must tell us "where the cocks come from " (Blacker). 
Mastoid TeEth.

Thirty-five years ago my curiosity was aroused by some strange teeth lodged in the mastoid region of a horse's skull. The specimen is preserved in the museum of the Veterinary College at Alfort, near Paris. The horse was dissected in the college, and the teeth were described by Professor Goubaux in 1849. On the sliull is written, "Supernumerary molars in the temporal region of a horse." I re-examined this skull and some other examples of mastoid teetl when I revisited the museum in 1917 From the day that I first examined these misplaced teeth, impacted in the mastoid portion of the temporal bone, my interest in them remained unabated. Teeth in this situation aro not novelties. I have examined a score of such specimens. . The presence of mastoid teeth is indicated by a sinus at the base of the ear (Fig. 7), from which purulent and mucous fluid issues. This leads to an examinution and the detection of the teeth. Sometines one tooth is present, lodged in the attic of the tympanum, a fact that lias given colour to the erroneous impression that the sinus and the misplaced tooth arise from imperfect closire of the branchial pouch from which the tym. panum is derived. Occasionally several teeth are present; they are invariably ill-formed, and two or more teeth may be blended, forming a mäss resembling an odontome enclosed in a bony capsule cmbedded in the mastioid region of the skull. Such dental conglomerates contain enamel, dentine, and cementum in a complex jumble. The dental mass sometimes bulges into the cranial cavity, and if the sinus becomes septic the horse dies from meningitis. The facial nerve is sometimes involved in the Fallopian aqueduct, and leads to facial palsy:

Vete. fuary surgeons remove mastoid teeth in a summary manner. They enlarge the simus, ascertain the position of the tooth, and remove it either with forceps or a chisel and mallet. The cavity is stuffed with antiseptic gauze and allowed to heal.

In 1890 I obtained some new light on theso curious teeth. Dr. John Evans of Aberdaie sent me a sheep's

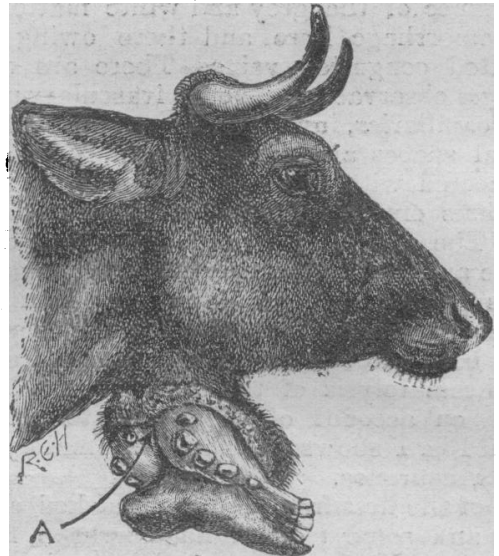

Fig. 10.-Head of a cross-bred Devon ox with an accessory head attached to its throat. A cane nassed through the accessory mouth entered the normal pharynx.

ear (Fig. 8) with a fistula corresponding in situation with the sinus in the mare. Near the orifice, and associated with it, there is an incisor tooth, in shape indistinguishable from the normal incisor of a lamb. The neck of the tooth is surrounded with mucous membrane (gum), and its root occupies a bony socket; the whole is lodged in a fold of skin beset with black papillae. This fold of skin resembles. in every feature the lower lip of a lamb. The rest of the head had been lost, probably eaten, The ear, when shown at a meeting of the Pathological Society, London, caused comment and vague speculation. Many years elapsed before $I$ got any clear light on this specimen, and the clue gradually csme from a study of double-headed animals.

The teratological collection in this museum is the finest in the world. It was founded by Jolun Hunter, who took a keen interest in monsters, not from curiosity, but as part of a great scheme showing the various phases of life. This collection includes monstrous beans, cuetumbers, and apples; eels azd salmon, carp and shark, crabs and lobsters, =lizärds and snakes, sparrows and pigeons, chioks and dncklings, kittens and pups, .. lions and lambs, hares and rabbits; sheep and rams, cowis and ealves, monkeys and men. Many are so misshapen that we may, with Job, ask who gendered them. The most extraordinary specimen is the skull of a double-headed child obtained from Bengal (Fig. 9); Mr. Shattock legards it as the most wonderful specimen in the museum, and he is a competent judge. The remarkable history of the unfortunate:child is given at length in the catalogue.

Hunter noted that some malforma tions are common in certain genera of animals. Double-headed liorses, oxen, and sheep are common. During the last thirty years I have exa. mined a hundied specimens in museums, dissecting rooms, and penny shows.

In 1877 Gurlt published some observations on malformations among domesticated animals-and figured the head of a lamb with incisors lodged in a diminutive but unmis takable mandible, and a tongue of corresponding size. The inandible, teeth, and tongue were associated with

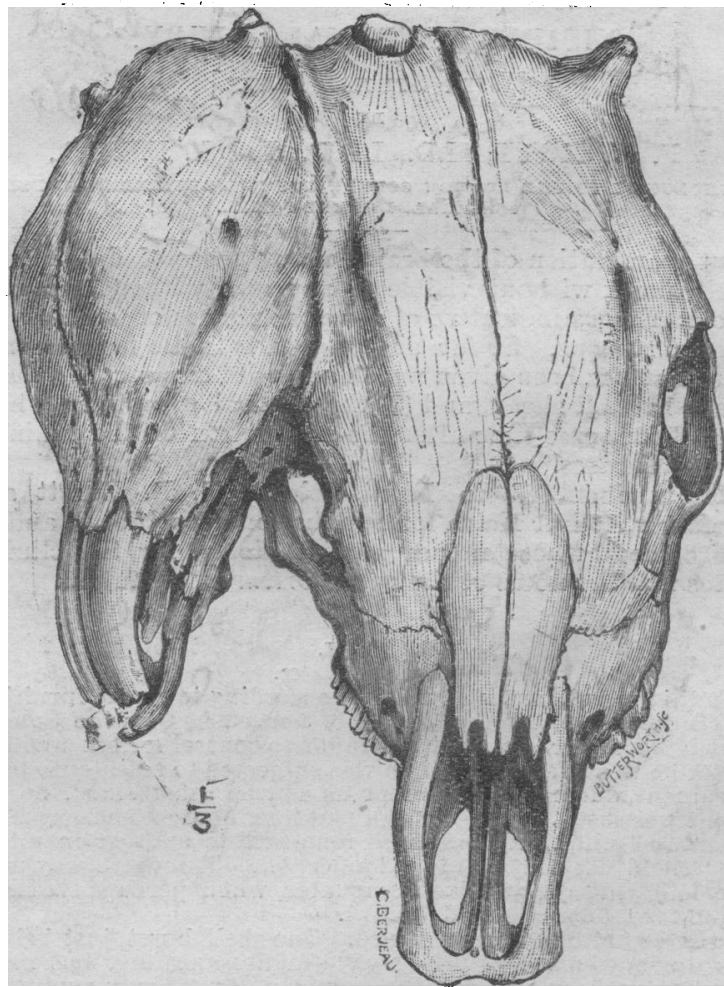

Frct. 11.-Calf's skull with an accessory skull attached in the mastoid region. (Museum, Royal College of Surgeons.)

a fistula opening into the normal pharynx of the lamb. When the animal drank, some of the fluid escaped through the fistula. A similar condition is shown in Fig. 10, except that the subject is a cow of the Deron breed. This coir 
was exhibited in a travelling show. Attached to the neck is a mandible with teeth and tongue; an orifice associated with the tongue led into the cow's pharyux. A study of this and similar recorded examples leadis me to endorse Gurlt's opinion, that these cervical tecth, mandible, and tongue arie reminants of an accessory head and the fistula represents the mouth of the rudimentary head. The inuseum contains some admirable examples of bicephalous skulls of calves. These double skulls are remarkable from the constancy with which they are conjoined in the mastoid region. A useful specimen shows a well-formed skull, with one less perfectly developed, firmly fused to it in the mastoid region (Fig. 11).

'The critical stindy of a laige number of such skulls leaves no escape from the conclusion that mastoid teeth and an auricular sinus in horses, like a cervical ostium and teeth in a sheep or an ox, are remnants of an accessory or parasitic head. Mastoid teeth are memorials of a lost individual.

T'eeth are conspicuous and easily recognized. They develop and calcify during fetal life into resisting structures and serve as useful signs. This is illustrated by a monstrous pig I dissected and added to the Teratological Gallery in 1888. "The pig in external appearance is double in all parts except the head and neck. I made a complete examination of the head and found a pair of fused maxillae impacted between the normal jaws, and felt convinced that an accessory mandible existed somewhere about the pig's head. At last I found a rudimentary parasitic mandible, with teeth hanging like a polypus in the pharynx, and attached by a narrow pedicle to the base of the skull. It is the oddest example of a misplaced organ that has come under my notice.

If Professor Keith accepts my explanation of the origin of mastoid teeth, he will realize that they are misplaced in the Dental Collection. Their proper place in this museum is the Teratological Gallery.

\section{THE MICROSCOPIC EXAMINATION OF}

\section{THE BRAINS OF TWO MEN DEAD OF COMMOTIO} CEREBRI (SHELL SHOCK) WITHOUT VISIBLE EXTERNAL INJURY.*

\section{[With Special Plate.]}

$B \mathbf{Y}$

F. W. MOTT, M.D., LL.D., F.R.S., F.R.C.P.,

PATHOLOGIST TO THE LONDON COUNTY COONCIL ASYLCMS, MAODSLEY HOSPIFAL, DENMARK HILL.

The examination of the brains of two cases of death from shell shock without visible injury and without punctate haemorrhages indicative of gas poisoning is of interest for several reasons. So far as I know, it is the first description that has been given which serves to explain (1) sudden death in shell shock, and (2) the clinical symptoms which persist for some time after the commotion of the brain in non-fatal cases.

I am indebted to Lieut.-Colonel T. R. Elliott and Professor Arthur Keith for sending me the brains, and to the officers whose names are mentioned for the clinical notes and the notes of the post-mortem examination.

\section{CASE I.}

Clinical Notes.

In this case the man developed, according to a notefurnisher by Captain J. London, a degree of nervousuess on the Somme which lie never lost, but was able to control for" six months. Later he was in an area which was subjected to an intense bom bardment, during which, as far as can be ascertained, no gas shells were used. This lasted about four hour's (February 22nd, 4 p.m. to 8 p.m.). Although he remarked to another man that he "could not stand it much longer," he did not give way until the following day, twelve hours later, when perhaps six shells came over (February 23rd, 8 a.m.).

He was not buried nor gassed. One shell burst just behind his dug-out-namely, $10 \mathrm{ft}$. away-in the moruing, but many must have been as near the previuus day. Early symptoms were tremors and general depression. The later symptom (February 22nd) - were coarse tremors of the limbs, crying (February 23rd), inability to walk or do anything. He would not answer questions-very like the-hysterical manifestations of melancholia. The pupils were dilated. Captein London'states

* The expenses connected with this investigation were defrayed cut of a Governmentetarit of the Board of Cojitrol. that he was rather busy with some wounded at the time, and did not make a detailed examination.

A note by Captain Francis A. Duffield, R.A.M.C.(S.R.), states that the man was admitted to the field ambulance in the evening in a state of acute mania, shouting "Keep them back, keep them back." He was quite uncontrollable and quite impossible to examine. He was quieted with morphine and chloroform, and got better and slept well all night. In a later̂. note Lieut.-Colonel J. F. Crombie, in command of the field ambulance, stated that the patient had at least two hypodermic injections of morphine while in the ambulance. Next moluing he woke up apparently well, and suddenly died.

\section{Necropsy.}

- The following is a report by Captain A. Stokes; R.A.M.C. (Mobile Laboratory); on the post-mortem examination, made on he afternoon of the day of death:

There were no marks of external violence on the body other In some small scratches on the anterior chest wall.

Thorax.-The lungs were oedematous, and in the substance of the lower lobe of the left lung there was a considerable haemorrhage. The right luing, except for oedema, was normal.

Heart.-Enlarged, and the right side dilated. The muscle was good, and there was no valvular lesion.

Abdominal Cavity.-Normal. There was no pathological cliange in the stomach, oesophagus, intestine, or great intestine. The liver was normal in size, and was somewhat cons gested. The spleen was normal. The kidneys were small, but showed no gross change. "The urine contained neither sugar nor albumin.

Skull. - There was a slight bruise on the scalp, in the frontal region. The brain was extremely congested, and on each side of every superficial vessel there was an ecchymosis. There were a number of minute punctiform haemorrhages at the terminations of the smallest vessels on the surface of the brain. The whole brain was soft but not markedly oedematous. The cerebro-spinal fluid appeared to be blood-tinged. There was considerable ecchymosis on each side of the great sinuses of the skull. There was no large haemorrhage found, and no small intracerebral petechiae. There was no gross lesion of tho viscera, which would have been a cause of death; but though
I have never seen a post-mortem examination on a man who has clied of "shell shock," I consider the condition of the brain is consistent with that diagnosis.

Mrcroscopic Examination of the Brain of Case I.

The brain had been preserved in Kaiserling's fluid, and it was not in very good condition, but seeing that it was placed in this fluid less than twelve hour's after death, it is probable that the portions examined yielded satisfactory material for microscopic investigation.

The portions of brain selected were prepared for section by the paraffin method of serial sections. The dyes used to stain the sections were as follows: (1) Haematoxylin and eosin, (2) Van Gieson, (3) thionin, (4) polychrome and eosin. The sections were $5 \mu$ in thickness and were mounted, after staining, in Canada balsam.

Cerebrum: Top of Ascending Frontal Convolution-Leg Area.-The veins are congested both in the meninges and in the substance of the grey and white matter. There is subpial haemorrhage here and there owing to rupture of the dilated congested veins. There are no punctate haemorrhages observable. The perivascular spaces of the arterioles, capillaries, and venules are dilated, also the perineuronal spaces are distinctly seen, some being apparently connected with the perivascular spaces. In some of the sections empty collapsed vessels can be discerned. in places. The general appearance suggests deficiency of blood in the arteries and capillaries, with engorgement of the venous system. $A$ condition very similar to that observed in experimental anaemia in animals produced by ligation of both carotids and vertebrals. There is some degree of chromatolysis of the cells. The Betz cells are the easiest, on account of their size, to recognize this change, and Fig. 1 shows the early chromatolysis of these psychomotor neurones.

The pole of the first frontal shows marked congestion of the vessels and some subpial haemorrhage from dilated congested reins. Many of the arterioles and capillaries are empty and collapsed, and there is the same appearance of dilatation of the perivascular sheaths and perineuronal spaces. The pyramidal cells also show early chromatolytic changes.

Internal Capsule.-There is general congestion of roins, and the small vessels appear to be either empty and collapsed, or contain less blood than nornial. Some of the vessels show haemorrhage into the sheath. (Fig. 3.)

Corpus Callosim.-The small vessels are congested and dilated, some liave ruptured into the slieath, other small vessels have ruptured into the tissue. There are no typical punctate haèmorrhages such as are secn in gas 